EESTI NSV TEADUSTE AKADEEMIA TOIMETISED. XVII KOIDE

KEEMIA * GEOLOOGIA. 1968, Nr. 3

ИЗВЕСТИЯ АКАДЕМИИ НАУК ЭСТОНСКОЙ ССР. ТОМ XVII

Химия * ГЕология. 1968, ㅊ: 3

Т. ПЕХК, Э. ЛИППМАА

\title{
СПЕКТРЫ ЯМР УГЛЕРОДА-13 \\ И РАСЧЕТ ПО МЕТОДУ $\omega$-МО МЕТОКСИБЕНЗОЛОВ
}

\begin{abstract}
Исследованы спектры ЯМР углерода-13 метоксибензолов. Измерены химические сдвиги всех углеродных атомов. Произведены расчеты метоксибензолов по методу Хюккеля и $\omega$-методу; полученные $\pi$-электронные плотности сравнены с химическими сдвигами углерода. Сдвиги углеродных атомов, связанных с водородом. дают хорошую корреляцию с рассчитанными плотностями, однако $\pi$-электронные плотности углеродных атомов, связанных с кислородом, коррелируются со сдвигами углерода хуже. Сдвиг углерода метоксигруппы показывает зависимость от стерических факторов.
\end{abstract}

\section{Введение}

Химические сдвиги протонов и углерода ароматических соединений показывают линейную зависимость от плотности $\pi$-электронов на углеродных атомах $\left[{ }^{1}\right]$. Экспериментально показано, что существуют приближенные соотношения

$$
\begin{aligned}
& \delta_{\mathrm{H}}=Q_{\mathrm{H}} q_{r}, \\
& \delta_{\mathrm{C}}=Q_{\mathrm{C}} q_{r},
\end{aligned}
$$

где $\delta_{\mathrm{H}}$ и $\delta_{\mathrm{C}}$ соответственно химические сдвиги протонов и углерода, $q_{r}$

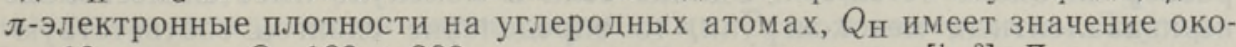
ло 10 м. д. и $Q_{\mathrm{C}} 160 \div 200$ м. д. на один $\pi$-электрон [1, ${ }^{2}$ ]. Для сдвигов углерода-13 имеется также теоретическое обоснование этой экспериментальной зависимости $\left[{ }^{3}\right]$. Влияние других эффектов на химические сдвиги (эффекты круговых токов, растворителя, анизотропии, поля и др.) делают, однако, проверку этого соотношения для протонов часто неоднозначной.

Әкспериментальная проверка зависимостей (1) и (2) является одним из направлений исследования факторов, определяющих химические сдвиги в ароматических молекулах. Однако при проверке (1) и (2), кроме указанных трудностей, проблематичным является также определение $\pi$-электронных плотностей. Концепция разделения $\pi$ - и $\sigma$-электронов при строгом рассмотрении подлежит критике, но все же находит довольно широкое и успешное применение. Нет также метода для определения «истинных» значений $\pi$-электронной плотности. Единственным критерием пока остается сравнение рассчитанных плотностей с экспериментом.

Хотя влияние других факторов, кроме $\pi$-плотностей, на сдвиги углерода-13 не столь велико, как на сдвиги протонов, для исследования соотношения (2) желательно применять соединения, у которых эти второстепенные эффекты имеют приближенно одинаковое значение. Для этой 
цели подходят производные бензола с одним типом заместителя. Из соединений этого типа одним из наиболее подходящих рядов являются метоксибензолы [ $\left.{ }^{4}\right]$, которые сравнительно легко синтезируются, имеют достаточную растворимость для снятия спектров углерода, а также довольно большие эффекты метоксигруппы на ароматическое кольцо. Кроме того, метоксибензолы достаточно стабильны (из-за нестабильности к окислению усложнено применение оксибензолов).

В работе [4] исследованы сдвиги протонов метоксибензолов и произведен их расчет по методу Хюккеля. Это дает удобную возможность сравнения протонных сдвигов со сдвигами углерода-13. Нами пронзведены дополнительно расчеты метоксибензолов по $\omega$-методу [5] с применением модификации Эттингера [6], что значительно ускоряет процесс достижения самосогласованности.

Одним из дополнительных факторов при исследовании метоксибензолов являются стерические эффекты, которые несомненно оказывают влияние на химические сдвиги и этим дают возможность изучить связь стерических влияний с химическими сдвигами.

\section{Экспериментальная часть}

a) Спектры ЯМР.

Протонные спектры. Для проверки синтезированных метоксибензолов, а также некоторых промежуточных продуктов синтеза были сняты спектры ЯМР-спектрометром на частоте 40 Мгц [13]. Для сравнения сдвигов протонов со сдвигами углерода использовались данные, полученные в работе [ $\left.{ }^{4}\right]$ при $60 \mathrm{Mгц.}$

Спектры углерода-13. Спектры были сняты на частоте 15,1 Мәц при естественном содержании изотопа $\mathrm{C}^{13}$, на универсальном спектрометре с диапазоном частот от 1,5 до 26 Мәц, работающем по методу разделения времени $\left[{ }^{14}\right]$.

Для получения спектров применялся обычный для спектроскопии углерода-13 метод быстрого адиабатического прохождения. Скорость развертки около 15 гц/сек. Однако если в молекуле имеется несколько неэквивалентных метоксигрупп, то определение сдвигов соответствующих углеродных атомов часто не удается из-за небольших различий в химических сдвигах, сравнительно широких линий и худшего отношения сигнал-шум вследствие квадруплетного расщепления углеродных сигналов. В этих случаях использовался двойной резонанс в условиях быстрого прохождения с сильным возмущающим полем $\left[{ }^{15}\right]$. Использованием двойного резонанса удается также получать сигнал абсорбции с удовлетворительным отношением сигнал-шум. На рис. 1 виден спектр двойного резонанса (абсорбционный сигнал) при сравнительно быстром прохождении (15 $ә$ ц/сек) 1,2,4-триметоксибензола. Частота возмущающего поля перестраивалась во время развертки один раз. Видны три группы сигналов: 1) в наиболее низком поле - сигналы от трех углеродных атомов, связанных с метоксигруппами; 2) в средней части сигналы от трех углеродных атомов, связанных с водородными атомами и 3) сигнал в наиболее высоком поле, принадлежащий трем атомам углерода метоксигрупп, один из которых можно выделить по форме сигнала.

Так как хлороформ является довольно хорошим растворителем, не имеющим заметных эффектов на углеродные сдвиги анизола $\left[{ }^{16}\right]$, то спектры твердых метоксибензолов были сняты как насыщенные раство- 


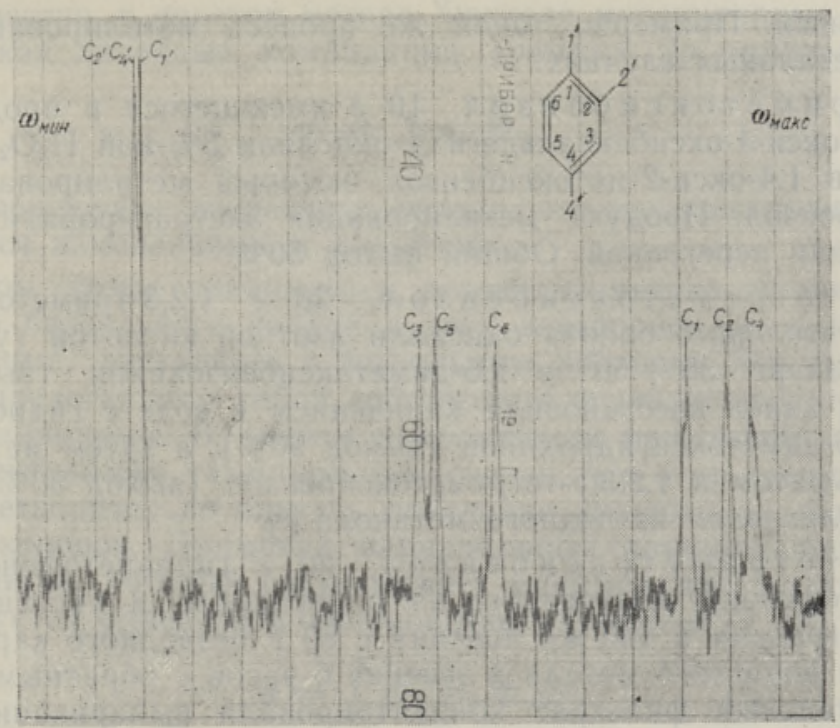

Рис. 1. Сигнал абсорбции двойного резонанса 1,2,4-триметоксибензола при скорости прохождения 15 гц/сек.

ры в хлороформе. Для снятия спектров применялись пробирки диаметром 15 мм; объем пробы 1,5-2 мл. Воспроизводимость результатов $\pm 0,5$ м. д. Все сдвиги измерены относительно внешнего стандарта сероуглерода. Хотя в литературе имеются данные о химических сдвигах анизола $\left[{ }^{16-18}\right]$ и диметоксибензолов $\left[{ }^{17}\right]$, эти соединения были измерены снова, так как между спектрами, измеренными ь разных лабораториях, имеются все же довольно большие различия в химических сдвнгах. Так, например, сдвиги углеродного атома $\mathrm{C}^{-1}$ анизола, измеренные в рабо$\operatorname{tax}\left[{ }^{17}\right]$ и $\left[{ }^{18}\right]$, различаются на 2,1 м. д. Результаты наших измерений находятся между этими двумя значениями. Если к измеряемым Лаутербуром сдвигам анизола и диметоксибензолов добавить 0,6 м. д., то получится хорошее совпадение: в 14 случаях из 17 различие не больше 0,2 м. д. Различие в 0,6 м. д. может быть сбъяснено применением Лаутербуром вторичного стандарта $\mathrm{K}_{2} \mathrm{CO}_{3}$.

\section{б) Метоксибензолы.}

Анизол (х. ч.), вератрол (1,2-диметоксибензол, х. ч.), диметиловый эфир резорцина (х. ч.) и диметиловый эфир гидрохинона (х. ч.) продажные продукты использовались без дальнейшей очистки.

$1,3,5$ - т р и м е т о к и и бе н з ол. $\mathrm{K} 8,7$ г $\mathrm{K}_{2} \mathrm{CO}_{3}$ (безводный) добавляли 2 г флороглицина в 20 мл сухого ацетона, перемешивали и нагревали до $50^{\circ} \mathrm{C}$, добавляли 5,2 мл диметилсульфата, нагревали в течение 3 часов, затем добавляли 20 мл воды и 2 мл конц. $\mathrm{NH}_{4} \mathrm{QH}$, перемешивали в течение 0,5 часа, добавляли воду, экстрагировали бензолом, перегоняли бензол и затем 1,3,5-триметоксибензол [7]. Выход $70 \%$.

$1,2,3$ - т р и м т о к и и енз ол. К 40 г сильно перемешиваемой смеси пирогаллола с 140 мл диметилсульфата и 100 мл метилового спирта добавляли 200 г $30 \%$-ной $\mathrm{NaOH}$ в теченне 3 часов при температуре $20 \div 25^{\circ}$. После разложения избытка диметилсульфата добавляли воду н при охлаждении получали практически чистый продукт [8]. Выход - 
количественный. Примерно такой же процесс метилирования примеияли и в остальных случаях.

1, 2, 4 - тр и метокси бензол. 10 г имеющегося в продаже ванилина (3-метокси-4-оксибензальдегид) окисляли $3 \%$-ной $\mathrm{H}_{2} \mathrm{O}_{2}$ по методу Дэкина [ $\left.{ }^{9}\right]$ в 1,4-окси-2-метоксибензол, который метилировали в 1,2,4триметоксибензол. Продукт метилирования экстрагировали бензолом, затем очищали перегонкой. Общий выход $50 \%$.

$1,2,3,5$ - те т р а ме ток с и ензол. 20 г 1,2,3-триметоксибензола в растворе этилового спирта окисляли азотной кислотой (уд. вес 1,2) при температуре $35 \div 50^{\circ}$ в 2,6-диметоксибензохинон (выход 90\%). Полученный хинон восстановили кипячением в воде с гидросульфитом натрия в 2,6-диметоксигидрохинон (выход 90\%), а затем метилировали диметилсульфатом в 1,2,3,5-тетраметоксибензол (выход 50\%), который перекристаллизовали из водного метанола [8].

$1,2,3,4$ - те тр а метокси бензол. 20 г галлацетофенона $(2,3,4$ триоксиацетофенон), полученного из пирогаллола и уксусного ангидрида $\left[{ }^{10}\right]$, нагревали в $100 \mathrm{~m}$ ацетона с 50 г безводного карбоната калия и 14 мл йодистого метила в течение 6 часов с обратным холодильником, ацетоновый фильтрат концентрировали выпариванием и разбавляли всдой. Получили $40 \%$ 2-окси-3,4-диметоксиацетофенона [ ${ }^{11}$, который при окислении $3 \%$-ной перекисью водорода [9] дал 1,2-диокси3,4 -диметоксибензол $(50 \%)$; метилированием последнего был получен 1,2,3,4-тетраметоксибензол (90\%).

$1,2,4,5$ - те тр аметоксибензол. 20 г $n$-бензохинона, 24 г свежерасплавленного измельченного хлористого цинка и 120 мл абс. метилового спирта нагревали с обратным холодильником в течение 0,5 часа. После охлаждения получили $50 \%$ 2,5-диметоксибензохинона [11], который восстанавливали гидросульфитом натрия в кипящей воде до 2,5-диметоксигидрохинона $(70 \%)$, метилированием последнего диметилсульфатом получен 1,2,4,5-тетраметоксибензол (90\%) [11].

Гексаметоксибензол. К смеси 9 г 2,6-диметоксибензохинона и 50 мл хлороформа добавляли 4 мл брома в 50 мл хлороформа. Хлороформ и непрореагировавший бром удаляли перегонкой, остаток фильтровали и промывали водой. Получали 2,6-диметокси-3,5-дибромбензоגинон $(80 \%)$, который нагреванием в метаноле с метилатом натрия дал $80 \%$ тетраметоксибензохинона $\left[{ }^{12}\right]$. Последний был восстановлен гидросульфитом натрия в тетраметоксигидрохинон, который метилировали диметилсульфатом, затем продукт экстрагировали бензолом и очищали перегонкой. Выход гексаметоксибензола из тетраметоксигидрохинона составил $30 \%$.

Чистота метоксибензолов проверялась на газовом хроматографе FB-4 фирмы «Шендон», на колонке с полиэтиленгликоладипатом, при температуре $170^{\circ}$.

Удобным методом идентификации метоксибензолов являлись их протонные спектры ЯМР, так как данные о сдвигах протонов метоксибензолов имеются в литературе [ [4].

\section{Расчеты}

Для изучения связи химических сдвигов с электронными плотностями на атомах углерода были проведены простые расчеты по методу MO (молекулярных орбиталей) Хюккеля и по $\omega$-методу [19]. Хотя данные расчета по методу Хюккеля имеются в литературе [4], для применения $\omega$-метода был повторен и расчет Хюккеля, как часть $\omega$-метода. 
Как известно, в простом методе Хюккеля молекулярные орбитали $\psi_{i}$ образуют как линейные комбинации атомных $2 p_{z}$-орбиталей $\Phi_{t}$, так что

$$
\psi_{i}=\sum_{u} c_{i u} \Phi_{u}
$$

а $\sigma$-связи исключают из расчета, считая, что все электронные эффекты описываются изменениями в $\pi$-системе.

В данном случае принимается делокализованная система из шести электронов бензольного кольца и двух электронов от каждого кислородного атома, связанного с бензольным кольцом. Эти молекулярные орбитали представляют собой собственные функции оператора Гамильтона для $\pi$-системы. В данном приближении применяют так называемый «эффективный» гамильтониан, считая, что этот гамильтониан может удовлетворительно описать поведение каждого из делокализованных $\pi$-электронов. Применяя вариационный принцип, находят набор коэффициентов, который соответствует минимальной энергии МО. При этом требуется определить кулоновские ннтегралы

$$
\alpha=\int \Phi_{u}{ }^{*} H_{e f} \Phi_{u} d \tau
$$

резонансные интегралы

$$
\beta=\int \Phi_{u}{ }^{*} H_{e f} \Phi_{v} d \tau
$$

а также интегралы перекрывания

$$
S_{u v}=\int \Phi_{u} \Phi_{v}{ }^{*} d \tau
$$

При простом методе Хюккеля (без перекрывания) считается, что $S_{u v}=\delta_{u v}$, кулоновским интегралам углеродных орбиталей присваивается условное значение $\alpha$, а резонансным интегралам связанных углеродных атомов - условное значение $\beta$; для не связанных в классической структуре атомов $\beta=0$. Если с $\pi$-системой углеродных атомов связаны $\pi$-электронные орбитали гетероатомов, то кулоновские и резонансные интегралы этих орбиталей определяются относительно соответствующих интегралов углеродных орбиталей:

$$
\begin{aligned}
& a_{\mathrm{X}}=\alpha+h_{\mathrm{X}} \beta, \\
& \beta_{\mathrm{CX}}=k_{\mathrm{CX}} \beta .
\end{aligned}
$$

В данном случае применены для кулоновского интеграла кислорода $h_{0}=2$ и для резонансного интеграла углерод-кислорода $k_{\mathrm{CO}}=0,8\left[{ }^{19}\right]$. Такие же $h$ и $k$ использовали Цвейг и др. [ [4]. Применяются и другие величины, например Форсеном и др. [20] принято при расчете метоксисалицилальдегидов $h=1,9, k=0,8$, Перельсоном и Шейнкером применяются $h=1,8, k=0,5\left[{ }^{21}\right]$, используются и другие значения $h$ и $k\left[{ }^{19}\right]$. В данных расчетах не изменяли величину $\beta$ со в полиметоксибензолах, которая уменьшается из-за стерических эффектов; эти изменения, однако, не являются критическими в расчетах по методу Хюккеля [4].

После решения векового уравнения получают коэффициенты $c$ в (3) и энергии МО. Коэффициенты $c$ определяют $\pi$-электронную плотность $q_{r}$ атома $r$ следующим образом:

$$
q_{r}=\sum_{j} n_{j} c_{j r}^{2}
$$

где $c_{j r}$ - коэффициент атома $r$ на $j$-й $\mathrm{MO}$, которая занята $n_{j}$ электро- 
нами. Суммирование производится по всем MO; можно рассчитать порядки $\pi$-связей и другие величины [19]. Основным недостатком метода Хюккеля является пренебрежение влиянием электронов друг на друга. Одним из наиболее простых методов для учета электронного отталкивания как функции распределения электронной плотности молекулы является $\omega$-метод [5], где величина кулоновского интеграла $\alpha_{r}$ связывается линейно с электронной плотностью атома $r$ :

$$
\alpha_{r}=\alpha_{0}+\left(1-q_{r}\right) \omega \beta,
$$

где $\omega$ является безразмерным параметром, величина которого обычно принимается равной 1,4 .

Согласно $\omega$-методу сначала получают распределение зарядов по методу MOX, на основе этого распределения вычисляют новые $\alpha_{\text {r }}$ по уравнению (10) и затем рассчитывают новое распределение зарядов. Итерационный процесс продолжают до тех пор, пока распределение зарядов не перестанет изменяться, т. е. до достижения самосогласованности. Однако $\omega$-метод применялся довольно мало, в основном для расчета ионизационных потенциалов углеводородов, углеводородных радикалов и ионов. Для молекул с гетероатомами он не применялся. Одним из недостатков этого метода является то, что при выбранной величине $\omega$ иногда не удается добиться самосогласованности [22]. Эттингеру [6] удалось простым приемом устранить этот недостаток и значительно уменьшить число итераций, требуемых для достижения самосогласованности. При этом расчет по МОХ и первая итерация выполняются, как обычно, но после этого электронные плотности этих двух вычислений усредняются:

$$
Q^{(1)}=\left(q_{r}^{\mathrm{MOX}}+q_{r^{(1)}}\right) / 2,
$$

и полученная $Q^{(1)}$ будет входной $q_{r}$ для следующей итерации. В общем

$$
a_{i}=a_{0}+\left(1-Q_{i}{ }^{(n)}\right) \omega \beta,(n+1) \text {-я итерация, }
$$

где

$$
Q_{i}^{(n)}=\left(q_{i}^{(n)}+Q_{i^{(n-1)}}\right) / 2 .
$$

Этот процесс продолжается до достижения самосогласованности, т. е. до тех пор, пока $q_{i}{ }^{(n+1)}$ отличается от $Q_{i}{ }^{(n)}$ для всех атомов не больше, чем на принятую величину $(0,001$ в данной работе).

Используя эти предположения, была составлена программа $\omega$-расчетов для ЭВМ Минск-2 на алгоритмическом языке МАЛГОЛ $\left[{ }^{23}\right]$; кроме $\pi$-электронных плотностей, вычисляются коэффициенты самосогласованных $\mathrm{MO}$, энергии $\mathrm{MO}$, общая энергия $\pi$-электронов, а также порядки $\pi$-связей. Получаемые в первом приближении $\pi$-электронные плотности Хюккеля отличаются от величин, рассчитанных Цвейгом и др. [ $\left.{ }^{4}\right]$, не больше, чем на 0,001 заряда электрона; $\omega$-расчеты проверяли сравнением с расчетами углеводородов по Эттингеру [6].

Регрессионный анализ производился по стандартной программе для ЭВМ «Минск-2».

\section{Результаты}

Результаты расчетов и измеренные углеродные сдвиги, а также протонные сдвиги $\left[{ }^{4}\right]$ приведены в табл. 1 .

При интерпретации спектров монорезонанса легко узнаются сигналы, соответствующие углеродным атомам, связанным с протонами, по их расщеплению в дублеты и квартеты, а также сигналы углеродных 
Химические сдвиги и $\pi$-электронные плотности в метоксибензолах

\begin{tabular}{|c|c|c|c|c|c|c|c|}
\hline \multirow[b]{2}{*}{$\begin{array}{l}\text { № } \\
\text { пा. }\end{array}$} & \multirow[b]{2}{*}{ Соединение } & \multirow[b]{2}{*}{$\begin{array}{l}\text { Углерод- } \\
\text { ный атом }\end{array}$} & \multirow[b]{2}{*}{$\tau$, м.д. } & \multirow[b]{2}{*}{$\delta_{\mathrm{cs}_{2}}$} & \multicolumn{3}{|c|}{$\pi$-электронные плотности* } \\
\hline & & & & & MOX & $\begin{array}{c}\text { Первое } \\
\text { приближе-- } \\
\text { ние } \omega \text {-ме- } \\
\text { тода }\end{array}$ & $\begin{array}{c}\text { Самосо- } \\
\text { гласован- } \\
\text { ное реше- } \\
\text { ние } \omega \text {-ме- } \\
\text { тода }\end{array}$ \\
\hline $\begin{array}{l}1 \\
2 \\
3 \\
4 \\
5\end{array}$ & Анизол & $\begin{array}{l}1 \\
2,6 \\
3,5 \\
4 \\
1^{\prime}\end{array}$ & $\begin{array}{l}-\overline{3}, 26 \\
2,80 \\
3,26 \\
6,26\end{array}$ & $\begin{array}{r}33,3 \\
79,2 \\
63,5 \\
72,6 \\
138,8\end{array}$ & $\begin{array}{l}0,955 \\
1,040 \\
0,998 \\
1,029 \\
1,940\end{array}$ & $\begin{array}{l}1,001 \\
1,039 \\
1,020 \\
1,035 \\
1,846\end{array}$ & $\begin{array}{l}0,986 \\
1,044 \\
1,014 \\
1,037 \\
1,862\end{array}$ \\
\hline $\begin{array}{l}6 \\
7 \\
8 \\
9\end{array}$ & $\begin{array}{l}\text { Вератрол }(1,2-д н- \\
\text { метоксибензол) }\end{array}$ & $\begin{array}{l}1,2 \\
3,6 \\
4,5 \\
1^{\prime}, 2^{\prime}\end{array}$ & $\begin{array}{l}\overline{3,25} \\
3,25 \\
6,23\end{array}$ & $\begin{array}{r}43,6 \\
81,3 \\
72,4 \\
138,0\end{array}$ & $\begin{array}{l}0,991 \\
1,040 \\
1,027 \\
1,943\end{array}$ & $\begin{array}{l}1,028 \\
1,063 \\
1,052 \\
1,856\end{array}$ & $\begin{array}{l}1,020 \\
1,060 \\
1,048 \\
1,872\end{array}$ \\
\hline $\begin{array}{l}10 \\
11 \\
12 \\
13 \\
14\end{array}$ & $\begin{array}{l}\text { 1,3-Диметокси- } \\
\text { бензол }\end{array}$ & $\begin{array}{l}1,3 \\
2 \\
4,6 \\
5 \\
1^{\prime}, 3^{\prime}\end{array}$ & $\begin{array}{l}3 \overline{72} \\
3,61 \\
2,95 \\
6,28\end{array}$ & $\begin{array}{r}32,3 \\
92,7 \\
87,1 \\
63,5 \\
138,8\end{array}$ & $\begin{array}{l}0,953 \\
1,081 \\
1,068 \\
0,996 \\
1,940\end{array}$ & $\begin{array}{l}1,018 \\
1,079 \\
1,070 \\
1,039 \\
1,853\end{array}$ & $\begin{array}{l}0,998 \\
1,088 \\
1,077 \\
1,026 \\
1,868\end{array}$ \\
\hline $\begin{array}{l}15 \\
16 \\
17\end{array}$ & $\begin{array}{l}\text { 1,4-Диметокси- } \\
\text { бензол }\end{array}$ & $\begin{array}{l}1,4 \\
2,3,5,6 \\
1^{\prime}, 4^{\prime}\end{array}$ & $\begin{array}{l}-\overline{3,31} \\
6,32\end{array}$ & $\begin{array}{r}39,1 \\
78,3 \\
137,8\end{array}$ & $\begin{array}{l}0,982 \\
1,038 \\
1,943\end{array}$ & $\begin{array}{l}1,028 \\
1,055 \\
1,861\end{array}$ & $\begin{array}{l}1,016 \\
1,054 \\
1,875\end{array}$ \\
\hline $\begin{array}{l}18 \\
19 \\
20 \\
21 \\
22 \\
23\end{array}$ & $\begin{array}{l}\text { 1,2,3-Триметокси- } \\
\text { бензол }\end{array}$ & $\begin{array}{l}1,3 \\
2 \\
4,6 \\
5 \\
1^{\prime}, 3^{\prime} \\
2^{\prime}\end{array}$ & $\begin{array}{l}- \\
3, \overline{5} 6 \\
3,18 \\
6,22 \\
6,28\end{array}$ & $\begin{array}{r}38,5 \\
53,9 \\
86,9 \\
68,9 \\
136,1 \\
131,6\end{array}$ & $\begin{array}{l}0,991 \\
1,029 \\
1,067 \\
1,024 \\
1,943 \\
1,946\end{array}$ & $\begin{array}{l}1,049 \\
1,060 \\
1,087 \\
1,068 \\
1,865 \\
1,868\end{array}$ & $\begin{array}{l}1,034 \\
1,058 \\
1,088 \\
1,057 \\
1,878 \\
1,883\end{array}$ \\
\hline $\begin{array}{l}24 \\
25 \\
26\end{array}$ & $\begin{array}{l}1,3,5-\text {-Триметокси- } \\
\text { бензол }\end{array}$ & $\begin{array}{l}1,3,5 \\
2,4,6 \\
1^{\prime}, 3^{\prime}, 5^{\prime}\end{array}$ & $\begin{array}{l}\overline{4,09} \\
6,30\end{array}$ & $\begin{array}{r}31,7 \\
101,0 \\
139,0\end{array}$ & $\begin{array}{l}0,951 \\
1,109 \\
1,940\end{array}$ & $\begin{array}{l}1,034 \\
1,106 \\
1,860\end{array}$ & $\begin{array}{l}1,009 \\
1,118 \\
1,873\end{array}$ \\
\hline $\begin{array}{l}27 \\
28 \\
29 \\
30 \\
31 \\
32 \\
33 \\
34 \\
35\end{array}$ & $\begin{array}{l}\text { 1,2,4-Триметокси- } \\
\text { бензол }\end{array}$ & $\begin{array}{l}1 \\
2 \\
3 \\
4 \\
5 \\
6 \\
1^{\prime} \\
2^{\prime} \\
4^{\prime}\end{array}$ & $\begin{array}{c}\overline{-} \\
3, \overline{65} \\
\overline{-} \\
3,38 \\
6,36 \\
6,28 \\
6,24\end{array}$ & $\begin{array}{r}49,2 \\
42,5 \\
92,8 \\
38,6 \\
90,2 \\
80,4 \\
136,4 \\
137,3 \\
137,3\end{array}$ & $\begin{array}{l}1,018 \\
0,988 \\
1,079 \\
0,980 \\
1,066 \\
1,037 \\
1,946 \\
1,943 \\
1,942\end{array}$ & $\begin{array}{l}1,053 \\
1,043 \\
1,098 \\
1,043 \\
1,086 \\
1,079 \\
1,870 \\
1,862 \\
1,867\end{array}$ & $\begin{array}{l}1,049 \\
1,030 \\
1,099 \\
1,026 \\
1,087 \\
1,069 \\
1,884 \\
1,876 \\
1,879\end{array}$ \\
\hline $\begin{array}{l}36 \\
37 \\
38 \\
39 \\
40\end{array}$ & $\begin{array}{l}\text { 1,2,3,4-Триметокси- } \\
\text { бензол }\end{array}$ & $\begin{array}{l}1,4 \\
2,3 \\
5,6 \\
1^{\prime}, 4^{\prime} \\
2^{\prime}, 3^{\prime}\end{array}$ & $\begin{array}{l}\overline{-} \\
3,58 \\
6,22 \\
6,26\end{array}$ & $\begin{array}{r}46,3 \\
50,5 \\
87,3 \\
137,6 \\
133,4\end{array}$ & $\begin{array}{l}1,016 \\
1,027 \\
1,064 \\
1,946 \\
1,946\end{array}$ & $\begin{array}{l}1,070 \\
1.076 \\
1,103 \\
1,876 \\
1,875\end{array}$ & $\begin{array}{l}1,060 \\
1,068 \\
1,097 \\
1,888 \\
1,877\end{array}$ \\
\hline $\begin{array}{l}41 \\
42 \\
43\end{array}$ & $\begin{array}{l}\text { 1,2,4,5-Тетрамет- } \\
\text { оксибензо. }\end{array}$ & $\begin{array}{l}1,2,4,5 \\
3,6 \\
1^{\prime}, 2^{\prime}, 4^{\prime}, 5^{\prime}\end{array}$ & $\begin{array}{l}\overline{3,57} \\
6,27\end{array}$ & $\begin{array}{r}49,7 \\
92,2 \\
136,5\end{array}$ & $\begin{array}{l}1.015 \\
1,078 \\
1,946\end{array}$ & $\begin{array}{l}1,068 \\
1,115 \\
1,875\end{array}$ & $\begin{array}{l}1,058 \\
1,109 \\
1,887\end{array}$ \\
\hline $\begin{array}{l}44 \\
45 \\
46 \\
47 \\
48 \\
49 \\
50\end{array}$ & $\begin{array}{l}\text { 1,2,3,5-Тетрамет- } \\
\text { оксибензол }\end{array}$ & $\begin{array}{l}1,3 \\
2 \\
4,6 \\
5 \\
1^{\prime}, 3^{\prime} \\
2^{\prime} \\
5^{\prime}\end{array}$ & $\begin{array}{l}\overline{-} \\
4,05 \\
\overline{6} \overline{23} \\
6,36 \\
6,32\end{array}$ & $\begin{array}{r}39,9 \\
61,3 \\
101,5 \\
37,8 \\
137,6 \\
132,8 \\
138,3\end{array}$ & $\begin{array}{l}0,988 \\
1,055 \\
1,106 \\
0,977 \\
1,943 \\
1,949 \\
1,943\end{array}$ & $\begin{array}{l}1,063 \\
1,082 \\
1,121 \\
1,057 \\
1,870 \\
1,881 \\
1,871\end{array}$ & $\begin{array}{l}1,043 \\
1,085 \\
1,127 \\
1,035 \\
1,882 \\
1,893 \\
1,883\end{array}$ \\
\hline $\begin{array}{l}51 \\
52\end{array}$ & $\begin{array}{l}\text { Гексаметокси- } \\
\text { бензол }\end{array}$ & $\begin{array}{l}1-6 \\
1^{\prime}-6^{\prime}\end{array}$ & $\overline{6,21}$ & $\begin{array}{r}49,7 \\
131,0\end{array}$ & $\begin{array}{l}1,051 \\
1,949\end{array}$ & $\begin{array}{l}1,110 \\
1,890\end{array}$ & $\begin{array}{l}1,100 \\
1,900\end{array}$ \\
\hline
\end{tabular}

* Для метоксигрупп дана величина заряда на кислородном атоме. 
Таблица 2

Рассчитанные по аддитивной схеме и наблюдаемые сдвиги кольцевых углеродных атомов в метоксибензолах.

\begin{tabular}{|c|c|c|c|c|c|}
\hline Соединение & $\begin{array}{l}\text { Угле- } \\
\text { родные } \\
\text { атомы }\end{array}$ & $\begin{array}{c}\text { Экспери- } \\
\text { ментальная } \\
\text { величина } \\
\text { сдвига } \\
\delta_{\mathrm{cs} 2}\end{array}$ & $\begin{array}{c}\text { Рассчитан- } \\
\text { ный сдвиг } \\
\delta^{\prime} \mathrm{Cs}_{2}\end{array}$ & $\begin{array}{c}\Delta= \\
=\delta \mathrm{cs}_{2}-\delta^{\prime} \mathrm{cs}_{2}\end{array}$ & 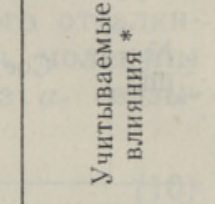 \\
\hline Вератрол & $\begin{array}{l}1,2 \\
3,6 \\
4,5\end{array}$ & $\begin{array}{l}43,6 \\
81,3 \\
72,4\end{array}$ & $\begin{array}{l}47,5 \\
77,7 \\
71,1\end{array}$ & $\begin{array}{r}-3,9 \\
3,6 \\
1,3\end{array}$ & $\begin{array}{l}c+o \\
o+M \\
M+n\end{array}$ \\
\hline 1,3-Диметоксибензол & $\begin{array}{c}1,3 \\
2 \\
4,6 \\
5\end{array}$ & $\begin{array}{l}32,3 \\
92,7 \\
87,1 \\
63,5\end{array}$ & $\begin{array}{l}31,8 \\
93,4 \\
86,8 \\
62,0\end{array}$ & $\begin{array}{r}0,5 \\
-0,7 \\
0,3 \\
1,5\end{array}$ & $\begin{array}{c}c+M \\
2 o \\
o+n \\
2 \mu\end{array}$ \\
\hline 1,4-Диметоксибензол & $\begin{array}{c}1,4 \\
2,3,5,6\end{array}$ & $\begin{array}{l}39,1 \\
78,3\end{array}$ & $\begin{array}{l}40,9 \\
77,7\end{array}$ & $\begin{array}{r}-1,8 \\
0,6\end{array}$ & $\begin{array}{l}c+n \\
o+M\end{array}$ \\
\hline $\begin{array}{l}\text { 1,2,3-Триметокси- } \\
\text { бензол }\end{array}$ & $\begin{array}{c}1,3 \\
2 \\
4.6 \\
\mathbf{5}\end{array}$ & $\begin{array}{l}38,5 \\
53,9 \\
86,9 \\
68,9\end{array}$ & $\begin{array}{l}46,0 \\
61,7 \\
85,3 \\
69,6\end{array}$ & $\begin{array}{r}-7,5 \\
-7,8 \\
1,6 \\
-0,7\end{array}$ & $\begin{array}{c}c+o+M \\
c+2 o \\
o+M+n \\
2 M+n\end{array}$ \\
\hline $\begin{array}{l}\text { 1,3,5-Триметокси- } \\
\text { бензол }\end{array}$ & $\begin{array}{l}1,3,5 \\
2,4,6\end{array}$ & $\begin{array}{r}31,7 \\
101,0\end{array}$ & $\begin{array}{r}30,3 \\
101,0\end{array}$ & $\begin{array}{c}1,4 \\
0\end{array}$ & $\begin{array}{l}c+2 M \\
2 o+n\end{array}$ \\
\hline $\begin{array}{l}\text { 1,2,4-Триметокси- } \\
\text { бензол }\end{array}$ & $\begin{array}{l}1 \\
2 \\
3 \\
4 \\
5 \\
6\end{array}$ & $\begin{array}{l}49,2 \\
42,5 \\
92,8 \\
38,6 \\
90,2 \\
80,4\end{array}$ & $\begin{array}{l}55,1 \\
46,0 \\
91,9 \\
39,4 \\
85,3 \\
76,2\end{array}$ & $\begin{array}{r}-5,9 \\
-3,5 \\
0,9 \\
-0,8 \\
4,9 \\
4,2\end{array}$ & $\begin{array}{c}c+o+n \\
c+o+M \\
2 o+M \\
c+M+n \\
o+M+n \\
o+2 M\end{array}$ \\
\hline $\begin{array}{l}\text { 1.2,3,4-Тетраметокси- } \\
\text { бензол }\end{array}$ & $\begin{array}{l}1,4 \\
2,3 \\
5,6\end{array}$ & $\begin{array}{l}46,3 \\
50,5 \\
87,3\end{array}$ & $\begin{array}{l}53,6 \\
60,2 \\
83,8\end{array}$ & $\begin{array}{r}-7,3 \\
-9,7 \\
3,5\end{array}$ & $\begin{array}{c}c+o+\mu+n \\
c+2 o+\mu \\
o+2 \mu+n\end{array}$ \\
\hline $\begin{array}{l}\text { 1,2,4,5-Тетраметокси- } \\
\text { бензол }\end{array}$ & $\begin{array}{c}1,2,4,5 \\
3,6\end{array}$ & $\begin{array}{l}49,7 \\
92,2\end{array}$ & $\begin{array}{l}53,6 \\
90,4\end{array}$ & $\begin{array}{r}-3,9 \\
1,8\end{array}$ & $\begin{array}{c}c+o+M+n \\
2 o+2 M\end{array}$ \\
\hline $\begin{array}{l}\text { 1,2,3,5-Тетраметокси- } \\
\text { бензол }\end{array}$ & $\begin{array}{c}1,3 \\
2 \\
4,6 \\
5\end{array}$ & $\begin{array}{r}39,9 \\
61,3 \\
101,5 \\
37,8\end{array}$ & $\begin{array}{c}44,5 \\
69,3 \\
99,5 \\
37,9\end{array}$ & $\begin{array}{r}-4,6 \\
-8,0 \\
2,0 \\
-0,1\end{array}$ & $\begin{array}{l}c+o+2 M \\
c+2 o+n \\
2 o+m+n \\
c+2 M+n\end{array}$ \\
\hline Гексаметоксибензол & $1-6$ & 49,7 & 66,3 & $-16,6$ & $+2 o+2 M+n$ \\
\hline
\end{tabular}

* $c=-31,7$ м. д.; $o=+14,2$ м. д.; $M=-1,5$ м. д.; $n=+7,6$ м. д.; сдвиг бензола $\delta \mathrm{Cs}_{3}=65,0$ м. д.

атомов, не связанных с протонами. Кроме того, в некоторых случаях исследование интенсивностей помогает однозначно определять сдвиги углеродных атомов. Вообще все сигналы группируются в три группы (см. рис. 1), четко отграниченные друг от друга:

1) метоксиуглеродные атомы $131 \div 139$ м. д.

2) С-Н-углеродные атомы $63,5 \div 101,5$ м. д.,

3) $\mathrm{C}-\mathrm{O}$ - -углеродные етомы $31,7 \div 61,3$ м. д. 
Эти соображения позволяют однозначно определить следующие 29 сдвигов углеродных атомов (номера соответствуют порядковым номерам табл. 1): $1,4,5,6,9,10,12,14,15,16,17,18,19,20,21,22,23,24$, $25,26,38,41,42,44,46,48,51,52$.

Кроме того, сдвиги 2 и 3 определены однозначно из спектра дейтероанизола $\left[{ }^{18}\right]$. Остальные сдвиги (всего 21) определяли, исходя из свойства аддитивности сдвигов углерода-13, широко используемого в анализе спектров углерода. В данном случае метоксигруппы проявляют значительные аномальные влияния, особенно при орто-положениях метоксигрупп, тем самым заметно нарушая аддитивность. Но зато сигналы от углеродных атомов тоже разделены на довольно большие интервалы. Учет каких-либо других факторов, например индуктивного влияния, может привести к неверным результатам. Как указывал Лаутербур в одной из своих последних работ [17], первоначальная интерпретация спектра вератрола была ошибочна $\left[{ }^{24}\right]$ именно потому, что интерпретацию давали, вероятно, по индуктивному эффекту.

В данном случае, как и в работе $\left[{ }^{17}\right]$, за основу для аддитивной схемы взят спектр анизола, из которого выявляются следующие эффекты (считая сдвигом незамещенного бензольного кольца 65 м. д.) метоксигруппы:

на связанный с метоксигруппой углерод (с в табл. 2) -31,7 м. д.

на орто-положение (о в табл. 2 ) $+14,2$ м. д.

на мета-положение ( $м$ в табл. 2) -1,5 м. д.

на пара-положение ( $n$ в табл. 2$)+7,6$ м. д.

Учитывая эти эффекты, а также эффекты, выявляющиеся из тех спектров ди- и полизамещенных метоксибензолов, где сдвиги определяются однозначно, удается определить сдвиги всех углеродных атомов. Результаты такого аддитивного расчета для кольцевых углеродных атомов приведены в табл. 2. Учитывая орто- и пара-влияния двух метоксигрупп, а также эффект «вклинивания» одной метоксигруппы между другими (парамагнитный сдвиг около 7 м. д.), можно определить оставшиеся неопределенными сдвиги метоксигрупп.

\section{Обсуждение результатов}

Сдвиги трех групп целесообразно рассмотреть раздельно.

1. Кольцевые атомы, не связанны е с метоксигруп пой. Сравнение рассчитанных сдвигов углерода с экспериментом (см. табл. 2) дает отклонения, характеризующие влияние метоксигрупп на соседние атомы. Можно считать удовлетворительным, если рассчитанные по аддитивной схеме сдвиги углерода отличаются от экспериментальных не больше чем на 2 м. д. Но, применяя простую аддитивную схему, надо иметь в виду, что даже в анизоле приходится учитывать стерическое взаимодействие между метоксильным углеродным атомом и o-углеродом $\left[{ }^{16}\right]$. Здесь имеется конфигурация $\mathrm{C}_{1}^{\prime}-0-\mathrm{C}_{1}-\mathrm{C}_{2}$, примерно аналогичная конфигурации $\mathrm{C}_{1}^{\prime}-\mathrm{C}_{1}-\mathrm{C}_{2}-\mathrm{C}_{2}^{\prime}$ о-ксилола, где стерический эффект сдвигает сигналы метиловых групп на 1,3 м. д. в сильное поле. Относительные расположения метоксигрупп в ди- и полизамещенных метоксибензолах неизвестны, и таким образом усиление стерических взаимодействий с $\mathrm{C}-\mathrm{H}$-группой, находящейся рядом с о-метоксигруппами, можно предвидеть только качественно. Әто и отра- 
жается в отклонениях от аддитивной схемы, так как сигналы всех C-Н-групп данного типа сдвигнуты в сильное поле. Если рядом

c С-Н-группой нет взаимодействующих о-метоксильных групп, то отклонения от аддитивности имеют меньшую величину ( $<2$ м. д.). Исключением является сигнал от С-5 в 1,2,4-триметоксибензоле, где имеется сильный диамагнитный сдвиг на 4,9 м. д., хотя рядом с С-5 нет двух 0 -метоксигрупп. Интересно, что и в протонном спектре 1,2,4-триметоксибензола имеется сильно аномальный сдвиг протона, связанного c. C-5 [ $\left.{ }^{4}\right]$. Сравнение сдвигов углерода с рассчнтанными электронными

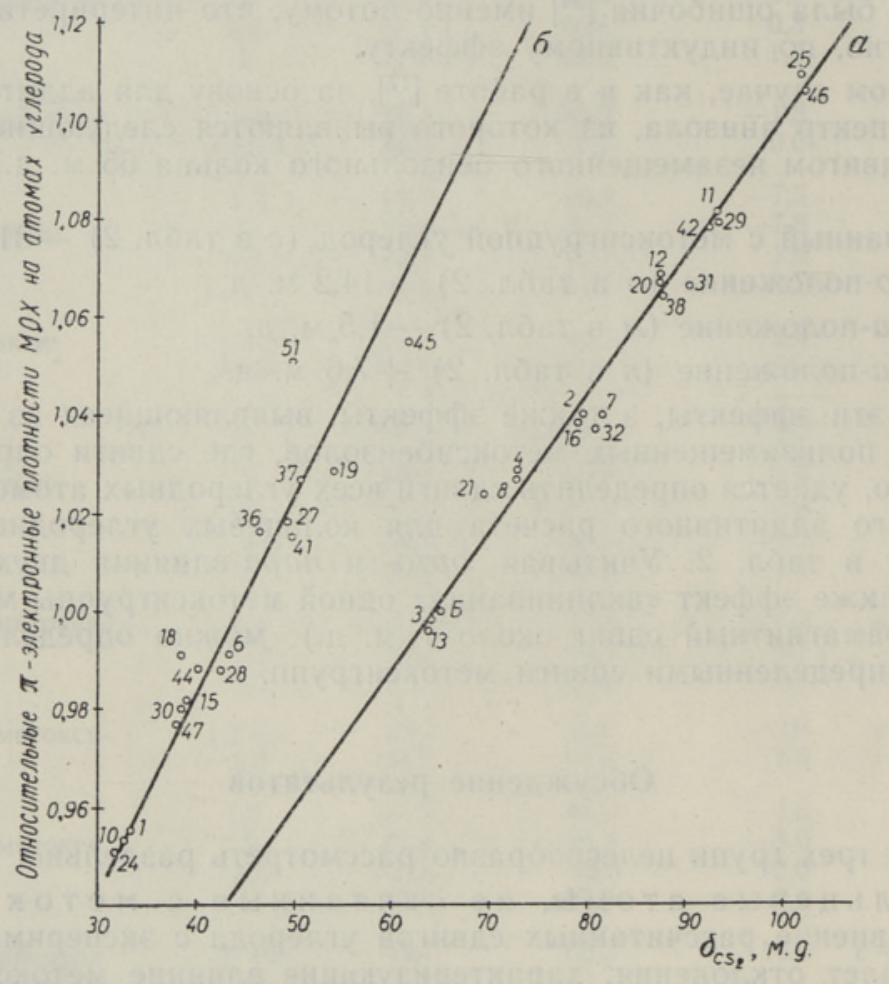

Рис. 2. Относительные л-электронные плотности МОХ и химические сдвиги кольцевых атомов углерода: $a$ - не связанных с метоксигруппой, 6 - связанных с метоксигруппой. Номера соответствуют порядковым номерам табл. 1. Б- бензол.

плотностями MOX приведено на рис. 2 (линия $a$ ). Соответствующее уравнение, получаемое по способу наименьших квадратов (в расчет приняты все измеренные сдвиги), следующее:

$$
\delta_{\mathrm{CS}_{2}}=351,6 q_{r}-287,3
$$

и среднее отклонение в рассчитанных сдвигах составляет 1,8 м. д. Коэффициент корреляции для уравнения (14) $r=0,99$, что соответствует нижней границе превосходной корреляции, если использовать предложение 
Джаффе для оценки степени корреляции в расчетах реакционной способности [ ${ }^{25}$. Такое же сравнение со сдвигами протонов, учитывая все сдвиги, измеренные в работе [ $\left.{ }^{4}\right]$, дает корреляцию с $r=0,97$, со средним отклонением в 0,09 м. д. На более хорошую корреляцию углеродных сдвигов с $\pi$-гілотностями указывает, кроме $r$, и величина среднего отклонения. Из (16) следует, что относительному протонному сдвигу в 1 м. д. в метоксибензолах соответствует сдвиг на 35 м. д. углеродного сигнала, следовательно среднему отклонению 0,09 м. д. соответствует среднее отклонение углеродного сигнала в 3,1 м. д.

Величина рассчитанного химического сдвига на один $\pi$-электрон 352 м. д. чрезмерно большая и является несколько неожиданной, так как в общем метод Хюккеля дает преувеличенные электронные плотности по сравнению с усовершенствованными методами $M O$ [ $\left.{ }^{19}\right]$. Но если принять меньший интервал электронных плотностей на тот же интервал сдвигов, то получится еще больший сдвиг на один электрон. Аномально большой сдвиг на один электрон получается также при сравнении сдвигов напряженных углеводородов с электронными плотностями, рассчитанными по расширенному методу Хюккеля $\left[{ }^{14}\right]$.

Сравнением сдвигов углерода с $\pi$-электронными плотностями $\omega$-метода получаем корреляционное уравнение

$$
\delta \mathrm{Cs}_{2}=343,9 q_{r}-285,9
$$

c $r=0,95$ и со средним отклонением 3,6 м. д. Таким образом получилась несколько худшая корреляция, но сдвиг на один $\pi$-электрон практически не изменился.

Сдвиги ароматических атомов углерода хорошо коррелируются с соответствующими сдвигами протонов. По углеродным спектрам можно рассчитать сдвиги протонов на основании уравнения

$$
\delta_{\mathrm{H}}=0,0285 \delta \mathrm{Cs}_{2}+1,097
$$

среднее отклонение 0,1 м. д., $r=0,96$.

Эта удовлетворительная корреляция облегчает изучение обоих спектров. Кроме того, имеются заметные отклонения от линейной связи этих сдвигов, причины которых требуют дальнейшего изучения.

2. Кольцевые атомы углерода, связанные с метокс и г р уп по й. Как было показано выше, сдвиги этих углеродных атомов попадают в интервал от 31,7 до 61,3 м. д., что имеет аналитическое значение при количественном определении ароматических эфиров.

Такие сдвиги в низкое поле этих ароматических углеродных атомов могут быть связаны с частичной двоесвязанностью между С и О, т. е. резонансные структуры (I, II и III) имеют заметный вес при описании метоксибензолов. Углеродные атомы, соединенные двойной связью с кислородом, дают сигналы примерно от -15 до +20 м. д. от сероуглерода,

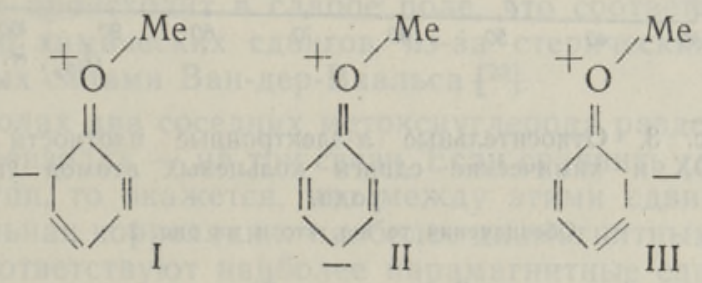

чем и объясняется частично сдвиг сигналов в слабое поле. Если между метоксигруппами нет стерических взаимодействий, то сдвиг углеродных 
атомов остается примерно постоянным (анизол, 1,3-диметоксибензол, 1,3,5-триметоксибензол). Во всех других случаях резонансные структуры I-III не могут иметь такого большого веса и поэтому сигнал от углеродных атомов соответственно сдвинется в сильное поле. С другой стороны, при стерических взаимодействиях влияние метоксигруппы не может быть настолько сильным, как в анизоле, и поэтому наблюдаются сдвиги в слабое поле. Следовательно, в данном случае можно предвидеть большие отклонения от аддитивности химических сдвигов. Отклонения от аддитивности (см. табл. 2) действительно довольно большие и достигают в гексаметоксибензоле 16,6 м. д.

Сдвиги углеродных атомов этого типа коррелируются удовлетворительно ( $r=0,96$, среднее отклонение 2,5 м. д.) с рассчитанными $\pi$-плотностями MOX по уравнению

$$
\delta \mathrm{Cs}_{2}=245,4 q_{r}-201,5,
$$

в котором сдвиг на один $\pi$-электрон приближается к общепринятому. Как видно из рис. 2. (прямая б), эти сдвиги образуют отдельную кривую, сдвинутую в слабое поле. Это показывает, что, кроме $\pi$-элєктронной нлотности, на сдвиг углерода оказывает почти константное влияние кислород (прямая поляризация $\sigma$-связи и другие эффекты).

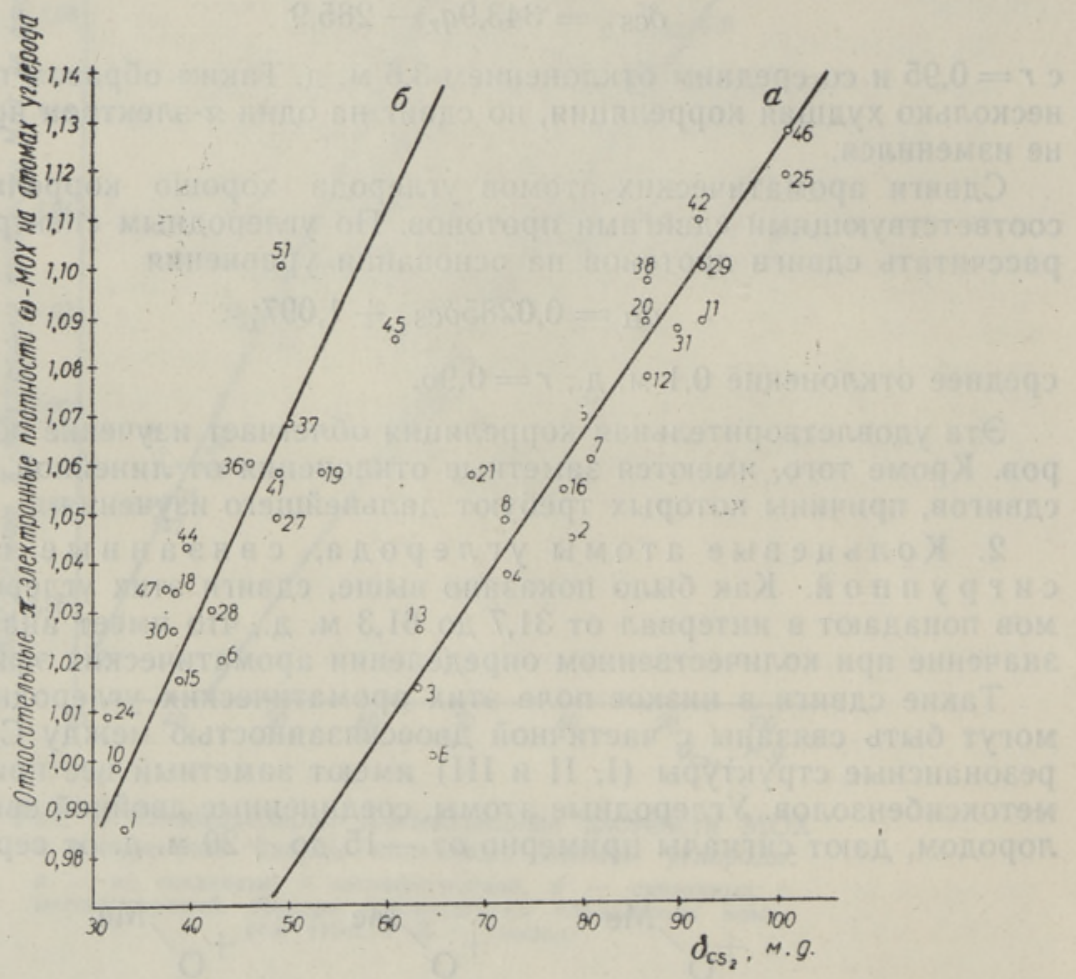

Рис. 3. Относительные $\pi$-электронные плотности $\omega$ MOX и химические сдвиги кольцевых атомов углерода.

Обозначения те же, что и на рис. 2.

По $\omega$-расчетам (см. рис. 3, прямая б) корреляция хуже ( $r=0,86$, среднее отклонение 4,3 м. д.), а сдвиг на один $\pi$-электрон в 234 м. д. сравним с соответствующей величиной расчетов MOX. 
Если сравнить $\pi$-плотности первого приближения $\omega$-метода (см. табл. 1), которое иногда с успехом используется для исследования свойств молекул [19], получим худшую корреляцию, чем при расчетах по MOX. Таким образом, $\omega$-метод не улучшает достигаемой по методу MOX корреляции. Только по ЯМР-спектрам метоксибензолов нельзя еще судить о неприменимости $\omega$-метода, хотя имеются довольно обоснованные теоретические аргументы о несостоятельности самосогласованности $\omega$ метода $\left[{ }^{26}\right]$. Для окончательного решения этого вопроса требуется глубокое исследование указанного метода, например варьирование $\omega$, изменение параметров $h$ и $k$ в уравнениях (7) и (8), так как при использовании метода требуются иногда другие величины параметров $h$ и $k\left[{ }^{19}\right]$.

Примерно такая же ситуация, как при сдвигах углерода, наблюдается и при протонных сдвигах. Если попытаться корригировать протонные сдвиги с учетом полевых эффектов, получается не улучшение, а ухудшение корреляции протонных сдвигов с $\pi$-электронными плотностями $\left[{ }^{4}\right]$.

3. А томы метоксигрупп. Сдвиги углеродных атомов метоксигрупп имеют наименьший диапазон сдвигов от 131 до 139 м. д., что все же гримерно в 50 раз больше соответствующих сдвигов протонов метоксигрупп $\left.{ }^{4}\right]$. Если сдвиги метоксипротонов не находятся в простой связи со структурой метоксибензолов, то по изменениям сдвигов углеродных атомов можно сделать некоторые выводы.

Две изолированные метоксигруппы в мета-положениях не влияют друг на друга. Это влияние сказывается, однако, в орто- и пара-положениях, притом примерно в одинаковой степени, что является несколько неожиданным. На аномальные эффекты в 1,4-диметоксибензоле указывают также измерения его диэлектрической релаксации [27]. Взаимодействие имеется даже между двумя метильными группами в $n$-ксилоле $\left.{ }^{28}\right]$.

При рассмотрении сдвигов метоксигрупп можно заметить большой парамагнитный сдвиг (около 7 м. д.) углерода метоксигрупп, находящихся между двумя другими метоксигруппами. Относительно конформаций метоксибензолов нельзя сказать ничего определенного. По измерениям дипольных моментов выяснено [29], что даже в анизоле атом кислорода не лежит в плоскости бензольного кольца, но судить о конформацнях диметоксибензолов по дипольным моментам невозможно. Этим и объясняется то, что для метоксибензолов неприменим простой конформационный анализ, использованный Вулфенденом и Грантом при исследовании метилбензолов [28].

Стерические взаимодействия в метилбензолах [28] имеют характер 1-4-взаимодействия в $н$-алканах, следствием чего является сдвиг в более сильное поле. Қак было указано выше, в анизоле имеется тоже взаимодействие этого типа, чем объясняется большой сдвиг орто-углерода в сильное поле. В метоксибензолах сдвиг метоксиуглеродов при стерических трудностях происходит в слабое поле, что соответствует принятому направлению химических сдвигов из-за стерических взаимодействий, описываемых силами Ван-дер-Ваальса [28].

В метоксибензолах два соседних метоксиуглерода разделены на пять связей, а в метилбензолах - на три связи. Если сравнить сдвиги метильных и метоксигрупп, то окажется, что между этими сдвигами имеется даже приблизительная корреляция: наиболее диамагнитным сдвигам метильных групп соответствуют наиболее парамагнитные сдвиги метоксигрупп. Это еще раз показывает, что стерические и конформационные факторы оказывают значительное влияние на углеродные сдвиги.

Сдвиги метоксигрупп коррелируются в некоторой степени с рассчи- 
танными $\pi$-плотностями на атомах кислорода, при этом большим плотностям $\pi$-электронов на кислороде соответствуют наименьшие сдвиги.

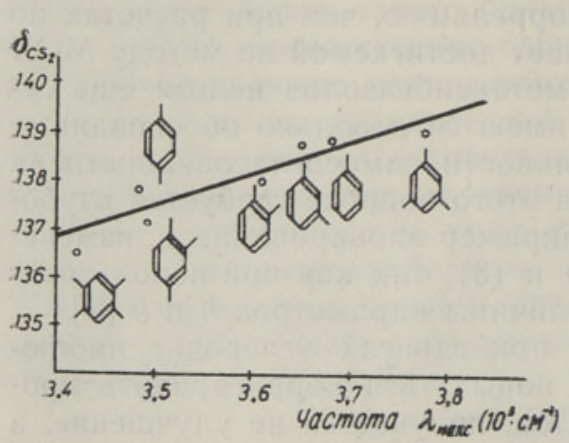

Рнс. 4. Частота наиболее интенсивной полосы поглощения энектронного спектра и химический сдвиг метокситрупп (у 1,2,4,5-триметоксибензола взято среднее из трех сдвигов).

Изменения сдвигов метоксибензолов можно сравнить с другими физическими свойствами молекул, чувствительными к стерическим факторам, например с электронными спектрами. При стерических трудностях уменьшается ннтенсивность поглощения соответствующей полосы и имеется сдвиг $\lambda_{\text {макс }}$ в наиболее коротковолновую часть спектра [30]. Связь между изменением пнтенсивности поглощения полосы около $260 м \mu$ и сдвигами углерода метоксигруппы в замешенных анизолах была показана в работе [ $\left.{ }^{16}\right]$.

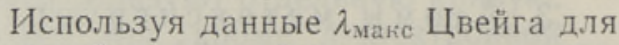
метоксибензолов «без стерических препятствий» (исключены 1,2,3-триметокси-, 1,2,3,4-тетраметокси-, 1,2,3,5-тетраметокси- и гексамето́ксибензол) [31], получаем приблизительную корреляцию сдвигов этих углеродных атомов с $\lambda_{\text {макс }}$ (рис. 4).

А. Цвейгом и др. $\left[{ }^{31}\right]$ показано приблизительное соответствие между $\lambda_{\text {макс }}$ и разницей энергии между наиболее высокой заполненной $\mathrm{MO}$ и самой низкой незаполненной МО метоксибензолов, рассчитанных по методу Хюккеля. Сдвиги углерода метоксигрупп, за исключением гексаметокси-, 1,2,3-триметокси-, 1,2,3,4-тетраметокси- и 1,2,3,5-тетраметоксибензола, приблизительно коррелируются с разницей этих энергий. Применение энергий $\omega$-орбиталей дает менее четкую корреляцию.

В заключение можно сказать, что изучение спектров ЯМР углерода-13 метоксибензолов дает полезную информацию об электронной структуре и стерических зффектах в этих молекулах.

Авторы выражают благодарность В. Салум за полезные указания и помощь в составлении программы для расчетов по ()-методу, а также Вычислительному центру Института кибернетики АН ЭССР за вычисления на ЭВМ Минск-2.

\section{Л ИТ Р РА У РА}

1. Spiesecke H., Schneider W. G., Tetrahedron Lett., 468 (1961).

2. La uterbur P., J. Am. Chem. Soc., 83, 1838 (1961).

3. Karplus M., Pople J. A., J. Chem. Phys., 38, 2803 (1963).

4. Zweig A., Lehnsen J. E., Lancaster J. E., Neglia M. T., J. Am. Chem. Soc., 85, 3940 (1963).

5. Whel a nd G. W., Mann D. E., J. Chem. Phys., 17, 264 (1949).

6. Etting er R., Tetrahedron, 20, 1579 (1964).

7. Cla rk-Lew is J. W., Australian J. Chem., 10, 505 (1957).

8. B a ker W., J. Chem. Soc., 662 (1941); CA, 36, 4306 (1942).

9. С е р ре й А., Справочник по органическим реакциям, Госхимиздат, 1962, с. 122.

10. Синтезы органических препаратов, Сб. 2, под редакцией Б. Казанского, ИЛ, 1949, c. 147.

11. Benington F., Morin R. D., Clark L. C., J. Org. Chem., 20, 102 (1955); CA 50, 3300 (1956). 
12. Robinson R., V a se y C., J. Chem. Soc., 660 (1941); CA, 36, 431 (1942).

13. Л и п п а а Э., Изв. АН ЭССР, Сер. физ.-матем. и техн. наук, 14, № 1,125 (1965).

14. Липпм а а Э., Пехк Т., Пас $345(196 \bar{\imath})$.

15. Rang S., Pehk T., Li p pma a E., Eisen О., Хим. Геол., 16, № 4, 346 (1967).

16. Dh a mi K. S., St others J. B., Can. J. Chem., 44, 2855 (1966).

17. La uterbur P., J. Am. Chem. Soc., 83, 1846 (1961).

18. Spiesecke H., Schneider W. G., J. Chem. Phys., 35, 731 (1961).

19. С трей твизер Э., Теория молекулярных орбит для химиков-органиков, «Мир», 1965.

20. Forsen S., Akermark B., A 1 m T., Acta Chem. Scand., 18, 2313 (1964).

21. Пе рельсон М. Е., Ш ейнке р Ю. Н., Теоретинеская и экспериментальная химия. 3, 697 (1967).

22. Streitwieser A., N a ir P. M., Tetrahedron, 5, 149 (1959).

23. Руководство по алгоритмическому языку МАЛГОЛ. Программы для ЭЦВМ «Мнск-2», вып. 4. Институт кибернетики АН ЭССР, Таллин, 1966.

24. L a ut erbur P., Ann. N. Y. Acad. Sci., 70, 841 (1958).

25. J a f f e H. H., Chem. Revs, 53, 191 (1953).

26. B a ir d N. C., Whit ehe a d M. A., Can. J. Chem., 44, 1933 (1966)

27. Grubb E. L., Smyth C. P., J. Amı. Chem. Soc., 83, 4873 (1961).

28. Woolfenden W. R., Grant D. M., J. Am. Chem. Soc., 88, 1496 (1966).

29. Aroney M., Le Fevre R. I. W., Shu-Sing Chang, J Chem. Soc., 3173 (1960),

30. Пространственные эффекты в органической химии, под ред. Ньюмана, ИЛ, 1960.

31. Z weig A., Lehnsen J. E., Murray M. A., J. Am. Chem. Soc., 85, 3933. (1963).
Ннститут кибернетики
Академии наук Эстонской ССР
Поступила в редакцию $12 /$ I 1968

\section{T. PEHK, E. LIPPMAA}

\section{METOKSUBENSEENIDE SUSINIK-13 TMR SPEKTRID JA $\omega$-MO ARVUTUSED}

Môõdeti ja analüüsiti metoksübenseenide süsinik-13 TMR topeltresonants-spektreid. Hückeli MO ja $\omega$-meetodi arvutustest saadud $\pi$-elektrontihedused korreleeruvad süsinik13 keemiliste nihetega. Aromaatsete süsinikuaatomite ja prootonite nihked on omavahel ligikaudselt lineaarselt seotud. Metoksüsüsinike nihked on mōjutatud steerilisest interaktsioonist metoksürühmade vahel. Viimaste nihked korreleeruvad elektronspektreist saadud $\lambda_{\max }$ väärtustega.

\section{T. PEHK, E. LIPPMAA.}

\section{THE CARBON-13 NMR SPECTRA AND $\omega$-MO CALCULATIONS OF METHOXYBENZENES}

The carbon-13 double resonance NMR spectra of methoxybenzenes have been obtained. The chemical shifts $\delta_{\mathrm{cs}_{2}}$ of all carbon atoms were measured on neat liquids or saturated solutions in chloroform. Hückel $M O$ and $\omega$-calculations of the $\pi$-electron densities were carried out and the results compared with the chemical shifts of carbon atoms. The ring carbon shifts were found to be proportional to the Hückel $\pi$-electron densities and in a lesser extent to the $\omega$ - $\pi$-electron densities. Good proportionality between proton and carbon-13 shifts was found in most cases. Aside from the $\pi$-electron charges, the methoxy carbon shifts are influenced by steric factors that shift the methoxy carbon resonance to lower field and are correlated with $\lambda_{\max }$ of electronic spectra. 